\title{
Umbanda: entre a cruz e a encruzilhada
}

\author{
LÍSIAS NOGUEIRA NEGRÃO
}

RESUMO: O artigo considera a umbanda, religião afro-brasileira de constituição recente, como estando dividida entre os apelos de suas raízes negras e os atrativos legitimadores da adoção dos princípios éticos cristãos. Embora pouco racionalizada e postulando uma visão de mundo predominantemente encantada, vem crescentemente moralizando-se a partir, sobretudo, das influências do ideal kardecista da caridade. Tal incorporação não é, contudo, linear, mas reinterpretada a partir da vivência concreta de seus agentes e moderada pela necessidade da cobrança por serviços religiosos prestados e pela "demanda", concepção mágica de conflito inter-individual.

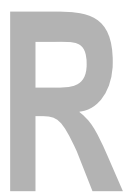

eligião brasileira (ver Concone, 1987), enquanto sincretismo nacional a partir de matrizes negras (macumba, candomblé) e ocidentais (catolicismo, kardecismo), é a umbanda também recente. A padronização inicial de seus ritos e seus prenúncios de institucionalização datam da década de 20 , quando kardecistas de classe média, atraídos pelos espíritos de caboclos e pretos-velhos que se incorporavam nos terreiros de macumba do Rio de Janeiro, neles adentraram e assumiram sua liderança. É possível que o mesmo tenha ocorrido em outros Estados, sobretudo no Rio Grande do Sul. Em São Paulo houve também movimentação semelhante, embora a partir de influências cariocas. Imediatamente os adventícios passaram a moldá-la à sua imagem e semelhança: branca, cristã, ocidental. Extirpam-se dos cultos os rituais mais primitivos ou capazes de despertar os pruridos da classe média (matanças de animais, utilização ritual da pólvora e de bebidas alcoólicas), moralizam-se os "guias", educando-os nos princípios da caridade cristã em sua leitura kardecista, racionalizam-se as crenças tendo-se por base a teodicéia reencarnacionista e organizam-se as primeiras federações que associam terreiros até então totalmente fragmentados.

UNITERMOS:

umbanda, religião, religiões afrobrasileiras, religiões populares, espiritismo.
Trabalho apresentado no XVIII Encontro Anual da ANPOCS GT Religião e Sociedade, novembro 1994.

Professor do Departamento de Sociologia da FFLCH-USP 
${ }^{1}$ Detalhes podem ser encontrados em Bastide (1971). Ver também Brown (1985).

2 Além do trabalho citado, ver também Bastide (1973).

${ }^{3}$ Acreditava existir em São Paulo entre 1944 e 1953, anos em que realizou seus levantamentos, "somente a Macumba individualizada e nem um centro de Espiritismo de Umbanda" (Bastide, 1973, p. XV). Para uma apreciação da obra do autor, além do trabalho citado na nota anterior, ver Negrão (1986).

${ }^{4}$ Ver Negrão (1973), tese da qual extraímos os dados apresentados no presente trabalho.
Já em 1941 realizou-se no Rio de Janeiro o Primeiro Congresso Nacional de Umbanda, nome então adotado para se fugir justamente do estigmatizado termo macumba. Participam deles umbandistas dos principais estados do sul e sudeste, sobretudo de São Paulo e Rio Grande do Sul ${ }^{1}$.

As interpretações sociológicas sobre o nascimento da umbanda assentam-se, como não poderia deixar de ser, em sua tríplice condição de religião nacional, surgida e consolidada no momento da expansão do sistema urbano industrial do segundo quartel do século, justamente nos centros urbanos mais importantes das regiões mais desenvolvidas do país. Roger Bastide, em sua análise que privilegia as relações raciais, considera a macumba como expressão mágica da marginalidade do negro no período pós Aboliçãoª ; já a umbanda, seria expressão ideológica da integração do mesmo à sociedade de classes nascente. Cândido Procópio Ferreira de Camargo, analisando-a também na mesma perspectiva integracionista mas tendo o kardecismo como modelo (Camargo, 1961), interpreta-a como forma de adaptação do migrante rural ou de pequenas cidades à vida nos grandes centros urbanos. Radicalizando a interpretação, em sua perspectiva estruturalista, Renato Ortiz (1991) a percebe como uma "exigência" de uma sociedade moderna, racionalizada e moralizada.

Em que pese as contribuições significativas dos autores para o conhecimento da realidade estudada, há que se apontar a insuficiência de suas perspectivas. Bastide toma como referência de suas reflexões uma concepção paradigmática de candomblé (ver Monteiro, 1978) e uma base empírica restrita, relativa às teses publicadas nos anais do Primeiro Congresso de Umbanda de 1941, desconhecendo a realidade da religião tal como cotidianamente vivida nos terreiros e reproduzindo sobre eles os preconceitos do noticiário jornalístico da época ${ }^{3}$. Seu discípulo Renato Ortiz, a partir de análise dos principais autores umbandistas (seus "intelectuais orgânicos"), diagnostica A morte branca do feiticeiro negro, incorrendo na mesma omissão de seu mestre. Foi C. P. Ferreira de Camargo quem melhor percebeu a complexidade do campo espírita, ao tentar dar conta de sua realidade através da noção do "continuum mediúnico" (Camargo, 1961) constituído entre o pólo branco, o kardecismo, e o pólo negro, a umbanda, com inúmeras fórmulas intermediárias (casos concretos de terreiros) entre eles. Apesar de seu instrumental teórico mais adequado à realidade estudada, sua preocupação predominante com o kardecismo, para ele paradigma do espiritismo, o impediu de melhor compreendê-la.

Nossas pesquisas ${ }^{4}$ têm demonstrado a complexidade da umbanda em São Paulo. Federações de terreiros e estes próprios constituem um subcampo específico dentro do campo religioso global, assumindo as primeiras o caráter de uma ortodoxia exercida por presidentes e líderes, frente à contestação mágica dos segundos, exercida pelos pais-de-santo. São os terreiros as instâncias criativas do culto, locus da construção mítica e ritual, onde a umbanda é vivida em seu cotidiano encantado de crenças e práticas mágicas, voltado para as necessidades de seu público interno. Constituem as federa- 
ções as instâncias de racionalização e moralização do culto, fiadoras do comportamento de umbandistas e seus "guias" em consonância com os padrões vigentes, tendo como orientação o público externo, na medida em que pretendem ser mediadoras entre o próprio culto e os agentes significativos da sociedade global.

Não obstante suas pretensões de unificação institucional, o movimento federativo paulista comporta mais de trinta organizações disputando a filiação dos mais de 10.000 terreiros existentes só na Capital. Sobressaem dentre eles duas organizações de caráter confederativo, filiando federações ${ }^{5} \mathrm{e}$ reivindicando o monopólio da representação legítima da umbanda junto ao Estado. Por outro lado, também não há homogeneidade de terreiros, que variam sobretudo em decorrência da condição social de seus membros ${ }^{6}$. Os terreiros de classe média tendem a ser os mais sensíveis ao discurso racionalizador e moralizador das federações, e os de periferia os menos. De uma maneira geral, contudo, as atitudes dos terreiros frente às federações, mesmo àquelas às quais são filiados, oscila entre a hostilidade e a indiferença.

Este bosquejo sobre o campo umbandista, embora ainda simplificador, demonstra sua riqueza. Não pode a umbanda ser reduzida à visão que dela têm as federações e seus intelectuais, não só por não ser esta unívoca, mas também por pouco influenciar os terreiros. A questão da respeitabilidade do culto e de sua legitimidade social somente lhes interessa em escassa medida. Passados os tempos da repressão policial aos cultos e tornada dispensável a proteção real ou virtual conferida pelas federações, apenas lhes importam o contato com seus "guias" nas sessões, seus conselhos e indicação de procedimentos mágicos de resolução de problemas. Para os terreiros as federações tendem a ser vistas como algo exterior à própria umbanda, cuja vivência se dá nas "giras", nos "passes", nas consultas aos guias, nos "trabalhos" a eles oferecidos. Não importa que sejam eles sérios como os caboclos, dóceis como os pretos-velhos, inocentes e bem humorados como as crianças, assustadores como os exus, desbocados e folgazões como os baianos, ébrios como os marinheiros e zés-pilintras ou mesmo sensuais e provocantes como as pombagiras. O importante é sua eficácia, não a qualidade moral do guia ou de seu aconselhamento. Por outro lado, a vivacidade e o caráter jocoso dos guias não moralizados têm um componente lúdico não desprezível, constituindo-se em fator de atração da clientela.

A umbanda dos terreiros é ainda um mundo encantado. São muito poucos os pais-de-santo que têm qualquer interesse secular (político, cultural) além do profissional. Analfabetos ou com baixo grau de instrução, a leitura de textos teológicos racionalizados e racionalizantes é quase inexistente. Apenas alguns deles em poucas tendas de classe média, dotados de maior nível de instrução formal e mais afeitos à reflexão abstrata, lêem e recomendam obras umbandistas, kardecistas e ocultistas. Em geral vivem imersos em seu mundo religioso. Sua realidade é a dos orixás, com os quais convivem no cotidiano das giras, dos trabalhos, das "demandas". Manipulam magicamente
5 Trata-se do SOUESP Superior órgão de Umbanda do Estado de S. Paulo e do SOUCESP - Supremo órgão de Umbanda e Candomblé do Estado de São Paulo.

${ }^{6}$ Dividimos os 87 terreiros amostrados em de classe média (29 ou $33,3 \%$ do total), de classes inferiores (38 ou $43,7 \%$ ) e de periferia - eufemismo para a condição de quase marginalidade de seus membros (20 ou 23,0\%). 
${ }^{7}$ Em nossa amostra, 32 dos 76 pais-de-santo consultados, ou $42,1 \%$ do total, encontram-se neste caso. Não se pode desprezar, contudo, a formação católica, religião de berço de 53 $(69,7 \%)$ dos mesmos. seus guias, respondendo às necessidades imediatas de seus filhos-de-santo e clientes. Tudo o que transcenda a isto, inclusive as atividades organizativas e institucionalizantes levadas a efeito pelo movimento federativo, salvo exceções, lhes desperta pouca ou nenhuma atenção. Seu imaginário e sua prática liga-se aos orixás e suas relações entre eles e os homens, aos meios mágicos de se protegerem e aos seus clientes. A racionalização dos terreiros é, portanto, muito embrionária. Limita-se quase sempre aos aspectos institucionais, dada a necessidade de se registrarem em cartório como entidades civis para poderem funcionar legal e livremente. Sendo pais e filhos-de-santo pouco afeitos ao trato com a burocracia, é neste momento que as federações se fazem necessárias, como despachantes especializados, atraindo novos e mantendo antigos filiados.

O mesmo não ocorre, no entanto, no que se refere à moralização: todos os terreiros, ou quase todos, parecem ter sido de alguma forma por ela atingidos. A idéia de um Deus transcendente e perfeito, a concepção de pecado, a incorporação de valores e atitudes cristãs, são amplamente generalizadas. Poder-se-ia pensar que tal fato dever-se-ia à atuação pedagógica e, no limite, repressiva, das federações sobre seus filiados. Tal não se dá, contudo, em razão do distanciamento entre umas e outros. Estes se furtam à orientação daquelas em questões rituais e doutrinárias, acatando com reservas apenas certas normas organizacionais (horários de funcionamento, presença de menores, utilização ritual de bebidas e da pólvora). As questões relativas ao culto (abertura e encerramento das sessões, tipo e ordem das giras, aconselhamento aos clientes e trabalhos mágicos realizados) são consideradas de competência exclusiva dos pais-de-santo ou dos próprios guias e as tentativas de padronização por parte das federações, ingerência indevida.

Constatamos que a grande influência moralizadora sobre a umbanda provém do kardecismo. Certamente uma grande quantidade de pais-desanto teve sua formação espírita e mediúnica inicial nas "mesas-brancas", aderindo posteriormente às giras 7 . Há também um número indefinido mas certamente bem elevado de simples médiuns iniciados nos salões kardecistas. A influência das idéias de Allan Kardec difusas no meio umbandista pode ser aferida pela generalizada presença da concepção de caridade. A sua prática é ao mesmo tempo a finalidade do culto e sua instância legitimadora. Incorporam-se os guias para que estes solucionem os problemas diversos (principalmente de saúde, mas também de dinheiro, trabalho, desajustamentos familiares e amorosos) que afligem a carente clientela. Ao praticar a caridade não são apenas os clientes os favorecidos, mas também os médiuns e os próprios guias que se elevam na hierarquia espiritual, garantindo no primeiro caso uma reencarnação mais favorável e no segundo caso, ascensão no mundo dos espíritos. A teoria kardecista da reencarnação e da evolução espiritual é o pano de fundo motivador da caridade umbandista. Sua prática é entendida, portanto, como missão, à qual os pais-de-santo gostariam de poder fugir, pois são muito restritivas da liberdade individual, mas à qual se submetem. 
A questão da caridade é fundamental no contexto das religiões moralizadas. Aparece, de certa forma, mesmo antes destas surgirem: Weber demonstra que mesmo os magos e rapsodos, como profissionais mais antigos do sagrado, "exaltam a generosidade dos ricos e maldizem os avaros". Na religiosidade ética, "a esmola é a parte mais universal e primária” (Weber, 1964, p. 455) da virtude religiosa, estando presente sua recomendação em todas as religiões mundiais: é um dos cinco preceitos absolutos de fé no Islão, é a "boa obra" no hinduísmo, no confucionismo e no judaísmo e "no caso do cristianismo primitivo adquiriu a dignidade de um sacramento"s. Somente com a expansão do cristianismo tornou-se possível o universalismo do amor, extensivo inclusive ao inimigo, mas este caso extremo permaneceu peculiaridade cristã.

O amor ao próximo como busca de salvação pode superar o casuísmo da esmola eventual e, mediante sua sistematização ética, criar um habitus, tal como ocorreu na religião de Zaratustra, no hinduísmo, no catolicismo e nas igrejas orientais, informa-nos ainda Weber. A prática das boas obras adquire "uma direção metódica racional de toda a vida e não em virtude de obras isoladas entre si” (Weber, 1964, p. 423). Importa não tanto as obras sociais em si mesmas mas a transformação operada na pessoa tendo por fim seu autoaperfeiçoamento.

O kardecismo parece enquadrar-se totalmente neste caso. Religião extremamente racionalizada desde a codificação espírita promovida por seu fundador francês na segunda metade do século XIX, inspirou-se na doutrina kármica hindu para explicitar o sentido da comunicação com os espíritos e no experimentalismo científico para captar suas mensagens ${ }^{9}$. Se o positivismo de Comte transformou-se de ciência em religião, o kardecismo teve trajetória inversa, sem deixar de ser religião e assimilando do positivismo inclusive seus elementos religiosos. Sua noção de caridade não é, também, em nada incompatível com as noções comtianas de bondade e altruísmo e seus princípios do amor e do viver para outrem (ver Comte, 1983). Uniu assim Kardec a evolução kármica, a mais eficiente teodicéia já imaginada pelo homem, conforme demonstrou Weber ${ }^{10}$, à ciência e à filosofia positivista, produzindo uma doutrina abrangente, ao mesmo tempo filosófica, política, científica e religiosa, palatável ao secularizado homem moderno. Tal fusão produziu, seguramente, a mais desencantada das religiões, pois os espíritos foram destituídos do patamar sobrenatural para o natural, do qual passaram a constituir sua dimensão invisível (ver Aubrée \& Laplantine, 1990, cap. IX).

Ao ser transladado para o Brasil, desenvolveu-se e difundiu-se muito mais que em seu país de origem, tendo acentuado seus traços religiosos e atenuado sua pretensão filosófica e científica. Permaneceu, no que se refere ao amor pelos vivos, grandemente interessado em obras sociais, mantendo hospitais, escolas e creches. Mas perdeu sua dimensão propriamente política, evitando os envolvimentos partidários ${ }^{11}$. No plano da caridade espírita, propiciada a vivos (práticas terapêuticas) e mortos (exortações para a prática do
8 "A esmola se apresenta para o rico como algo tão necessário para alcançar a bem aventurança que os pobres são considerados na Igreja quase como uma classe particular e imprescindível." (Weber, 1964, p. 455-456).

${ }^{9} \mathrm{O}$ mais completo estudo sobre o Kardecismo na França e no Brasil e suas inter-relações é La Table, le Livre et les Esprits, de Marion Aubrée e François Laplantine (1990). Nele encontram-se informações detalhadas sobre as fontes do pensamento de Kardec: a teoria da reencarnação, o evolucionismo, o positivismo e a pedagogia.

10 "A solução formalmente mais perfeita do problema da teodicéia que conhecemos, devemos à doutrina 'Karma' da Índia, à chamada crença na transmigração das almas" (Weber, 1964, p. 416).

${ }^{11}$ Aubrée \& Laplantine (1990) demonstram o contraditório engajamento dos espíritas franceses nos movimentos socialista utópico e liberal. Ver cap. XI. 
bem e doutrinação) mediante o contato mediúnico entre eles, concentrou seus conteúdos religiosos. Manteve assim o espírito pedagógico original do kardecismo, agora totalmente voltado para a educação moral e religiosa.

Herdeira da moralidade espírita via sua concepção de caridade, debate-se a umbanda com um dilema que lhe parece ser constitutivo. Para ser legítima, a prática da caridade deve ser, em princípio, totalmente desinteressada do ponto de vista econômico. Entretanto, freqüentemente os passes, as consultas e os trabalhos realizados no terreiro são cobrados. Os traços mágicos da umbanda, advindos de sua herança negra, validam as trocas econômicas entre pais-de-santo e sua clientela; quanto mais eficazes sejam eles na coerção dos poderes extra-empíricos no sentido da realização dos desejos daqueles que os solicitem, melhor sucedidos serão, inclusive economicamente. O caráter próspero de um terreiro é sinal de seu domínio sobre os espíritos; inversamente, seu domínio sobre estes abre caminho ao seu sucesso econômico. O progresso material depende da cobrança, mas esta não se coaduna à ética da caridade. O problema é a compatibilização dos extremos. Como exercer plenamente a caridade, se a montagem e a manutenção dos terreiros é dispendiosa, exigindo recursos de que raramente pais e filhos-de-santo dispõem? Como levantar os recursos sem comprometer o ideal? Entre a sobrevivência e o cumprimento da missão oscilam os umbandistas tentando uma fórmula conciliatória entre ambos.

A solução mais freqüentemente encontrada é a concessão de consultas particulares, realizadas fora das giras e tidas como infensas ao ideal da caridade. A elas só comparecem aqueles que sabem que serão cobrados e que, portanto, podem pagar. Muitas vezes o jogo de búzios ou de cartas também justifica a cobrança; paga-se por um serviço prestado, a prática divinatória. Cobrar-se de pobres, de necessitados, continua sendo atitude moralmente insustentável. Só é admissível se a pessoa puder pagar e não lhe vá fazer falta. Considera-se legítimo também receber-se o espontaneamente dado, em espécie (velas e bebidas, especialmente) ou dinheiro, a título de presente, gratificação ou esmola, mesmo que provindo de pessoas de escassos recursos. Neste caso o próprio doador é o árbitro de suas disponibilidades, além do que o pecado parece ser a cobrança, não o recebimento. Não obstante, mesmo quando se a faz, cobra-se pouco. Apenas o necessário para cobrirem-se as despesas do terreiro ou, no máximo, para a sobrevivência do pai-de-santo e de sua família, quando este não tem trabalho profissional. Como fonte de lucro, de enriquecimento, a cobrança é ilegítima. Não explorar é o lema.

Apesar de todos os subterfúgios para justificar-se a cobrança, ela é vista sempre com reservas. $\mathrm{O}$ interesse econômico pode conduzir à cobiça e à negação da caridade mas também, no caso extremo, ao seu inverso, a realização do mal contra inocentes. A caridade não se contrapõe apenas à cobrança, mas especialmente à utilização do poder espiritual para atividades tidas como malfazejas, independentemente do fato de serem ou não cobradas embora, neste caso, normalmente o sejam. Se nem todos os orixás, em conseqüência 
de sua condição de "guias de luz", espiritualmente elevados e, portanto, desprendidos do material, podem ser seduzidos por propostas do tipo do ut des, alguns deles, ainda presos às necessidades materiais e não dotados de consciência moral, as aceitam sem restrições ou constrangimentos. São eles especialmente os exus e as pombas-giras, mas também alguns baianos, marinheiros, zés-pilintras e ciganos, quando não "doutrinados".

Tais práticas consubstanciam-se na demanda ${ }^{12}$, expressão simbólica de conflitos reais, ou seja, utilização por alguém dos serviços dos orixás para defender-se dos seus desafetos e contra atacá-los. Raramente a intervenção dos guias é assumida como iniciativa dos demandantes, que consideramna uma resposta à ação mágica precedente, provocada pela inveja, ciúmes ou despeito dos rivais. Revidam ao agressor e este, enquanto tal, merece o mal que desejava contra sua vítima e que lhe é devolvido. A demanda embora persista mesmo na umbanda moralizada, é legitimada pelo merecimento do mal por parte de quem é por ele atingido. Pais-de-santo, mesmo dos terreiros mais mágicos e pouco moralizados, aceitam apenas demandar quando, após "correrem uma gira", convençam-se de sua justiça. A demanda implica no caráter conflituoso da vida cotidiana: há inimigos, há pessoas mal intencionadas. Não é errado agir contra eles, defendendo-se e contra atacando. Trata-se de justiça, não de maldade. Quem pratica o mal deve pagá-lo e não só no além, na próxima encarnação, mas aqui e agora. Assim como o bem que se busca, a cura, a resolução de problemas diversos, deve ser imediato, o castigo daquele que provocou o mal deve sê-lo também. Neste clima, todos os paisde-santo são "demandeiros" em potencial, decorrendo daí a desconfiança generalizada entre eles.

A caridade, ideal cristão filtrado pelo crivo kardecista, impregnou profundamente a ética umbandista. Praticá-la, fazer o bem a vivos e mortos é o único caminho para a evolução espiritual destes e daqueles. Não obstante, choca-se ela contra duas práticas tradicionais dentro do universo mágico no qual se constituiu: a cobrança pelos serviços religiosos prestados e a demanda, ou combate mágico a inimigos e desafetos. Ambas são necessárias: a primeira para a manutenção dos terreiros e a segunda porque há a necessidade de defesa e proteção dentro de um universo de relações hostil, regido pela inveja e pela concorrência.

O descompasso entre o ideal e a necessidade, entre o princípio e a prática, tem de ser superado. A originalidade da umbanda, sobretudo de seus terreiros de condição econômica inferior, é ter elaborado justificativas moralmente sustentáveis para fugir aos rigores do princípio da caridade kardecista por ela mesma incorporada. A reinterpretação se impõe: os valores não podem simplesmente ser transpostos para a prática, conduzindo a padrões efetivos que lhes sejam totalmente fiéis; a tradição negra, o peso do cotidiano e os interesses de pais-de-santo e clientes fazem-se sentir. Quanto à cobrança, não é o comércio religioso, em si mesmo, considerado condenável, pois é prática comum à maioria das religiões, inclusive ao catolicismo dominante. $\mathrm{O}$ mal

${ }^{12}$ Ver, sobre a demanda, Velho (1975). 
está em cobrar de quem não tenha ou a quem venha faltar, ou então cobrar excessivamente, mesmo que o pagante tenha recursos. A demanda, até certo ponto, também é vista como legítima. Desfaz o mal feito contra inocentes e o faz retornar contra quem o provocou.

Cobrança e demanda, quando indiscriminadas, podem conduzir ao malefício, pólo antagônico do benefício e negador do ideal da caridade. Para evitá-lo, sem abdicar de ambas as práticas, a justiça é invocada. É justo cobrar para cobrir despesas, quando quem cobra não tem recursos; é justo cobrar de quem pode pagar e de quem quer fazê-lo; é justo cobrar o que o trabalho vale. O injusto é a exploração, transformando o culto em fonte de lucro, cobrando excessivamente ou de quem não tem recursos.

É também justo defender o ofendido e punir o ofensor. Injusto é demandar contra o inocente, sobretudo em troca de pagamento. Não se trata da ética cristã do amor ao inimigo e da humildade, com sua aceitação passiva se não do mal, ao menos do agressor: trata-se da ética da justiça e da reparação do agredido mediante o castigo do responsável pelo ato maléfico. Tratase, em estrito sentido durkheimiano, de direito antes repressivo que restitutivo, totalmente distanciado da virtude cristã do perdão. A justiça é imediata, no aqui e agora, sem que se espere os castigos e as recompensas do além. Não existe também a mediação institucionalizada de aparato judicial: são os próprios guias e agentes mágicos os juízes e executores da pena. Justiça rápida, imediata, contando com a participação do ofendido que, ao reagir e ativar a manipulação mágica, assume papel decisivo no próprio processo. Além de eficaz na crença dos que a ela apelam e a ativam, tem a vantagem adicional de ser simbólica e, portanto, imputável do ponto de vista jurídico-racional. No mínimo tem o efeito catártico atribuído por Malinowski (1974) à magia.

A umbanda, embora mantendo em parte seu encantamento e magia, tende a ter moralizadas suas crenças e práticas. Em um número restrito de seus terreiros, sobretudo de classes médias, prevalecem os princípios cristãos-kardecistas do "voltar-se a outra face" e de "fazer o bem sem olhar a quem”. Na maioria deles tais princípios são, no máximo, referências ideais presentes no discurso mas não na prática, sendo esta orientada pela concepção de justiça mencionada, consentânea com o tipo de realidade de onde ela emerge: individualista, com predomínio do interesse econômico, competitiva e conflitual.

Não é a umbanda, contudo, na medida em que permanece dentro de cosmovisão encantada e mágica, voltada à satisfação das necessidades e desejos individuais, uma religião a-ética, como se poderia inferir a partir da análise clássica dos fenômenos mágico-religiosos. De fato, não estamos diante da simples reprodução dos quadros morais vigentes, em sentido durkheimiano: embora parta destes, deles se afastam sensivelmente ao admitir o justiçamento individual. Não se trata também de ética calcada em mensagem religiosa específica, capaz de exercer efeitos transformadores, como em Weber. A justiça praticada dentro dos quadros restritos aos litigantes 
não tem repercussões sociais de maior amplitude.

Apesar da amoralidade ser traço característico de seus agentes mágicos por excelência, os exus e as pombas-giras, sua eficácia, em princípio irrestrita, tende a ser contida por concepção específica de justiça. Não se trata, é claro, da tradicional moralidade cristã vigente em nossa sociedade, passiva e conformista, na expectativa da justiça divina. Trata-se de moralidade assentada no sentimento de justiça peculiar àqueles que vivem em meio basicamente competitivo, desprovidos de meios materiais necessários para enfrentar a luta cotidiana pela vida e superar os problemas que suscita. Embora estejam presentes dentro dos limites éticos umbandistas tanto as normas morais vigentes quanto as revelações religiosas que lhes são associadas, a umbanda assenta-se antes na vida real, no cotidiano de subalternos e carentes. É uma ética pragmática, que não opõe valores abstratos às restritivas relações concretas, mas que as reconhecem e aceitam como são: cobranças e demandas. A umbanda as toma como princípios válidos porque inevitáveis, apenas os disciplinando a ponto de não se oporem radicalmente aos ideais, também nela presentes em algum grau, do amor cristão e da caridade espírita.

A justiça, vista pela ótica dos subalternos, despossuídos, marginalizados ou precariamente dispostos nos lugares sociais, aparece assim como fundamento moral da prática mágica umbandista. Esta moralidade peculiar, que legitima a punição dos maus por suas próprias vítimas, está bastante distanciada da moralidade vigente, apesar dos linchamentos freqüentes e da ambígua presença dos "justiceiros” entre aqueles. A concepção religiosa predominante tenta obscurecer o caráter necessariamente mercantil das trocas religiosas e atribuir o castigo à vontade de Deus, aqui ou no além. No máximo, admite o castigo neste mundo à competência do Estado, de forma despersonalizada e formal. Na umbanda, não; a troca econômica é traço evidente e necessário, embora também obscurecida em alguns terreiros mais identificados às vigências religiosas. A prática do castigo aos ofensores pelos próprios ofendidos, mediante a utilização de recursos simbólicos, é peculiaridade sua, compartilhada com os demais cultos afro-brasileiros. Estamos, pois, distantes dos quadros de uma hegemonia moral que atrela os interesses individuais aos sociais e remete a justiça para além da competência das vítimas. Mas dentro de moralidade peculiar, que legitima o justiçamento inter-individual, prescindindo de mecanismos institucionais especializados, dificilmente acessíveis. Não se trata de ausência de moralidade, conforme se poderia legitimamente supor a partir da literatura sociológica clássica, mas de uma moralidade de aspiração, contrária (ou ao menos diversa) à estabelecida, autônoma e não heterônoma, como diria Georges Gurvitch (1956).

Recebido para publicação em setembro/1994 
UNITERIMS:

umbanda, religion, afro-brazilian religions, popular religions, spiritism.
ABSTRACT: The article considers Umbanda a recently formed afro-brazilian religion, devided between the pleas of its black roots and the legitimizing attractions of adopting Christian ethical principles. In spite of barely rationalized and alleging a predominantly enchanted view of the world, it has been becoming increasingly moralized, above all, as from influences of the Kardecist ideal of charity. Such an integration is not, however, linear, but reinterpreted as from the concrete experience of its agents and moderated by the need of requesting religious services rendered and by the "demand", magic concept of inter-individual conflict.

\section{REFERÊNCIASBIBLIOGRÁFICAS}

AubréE, Marion \& LaPlantine, François. (1990) La table, le livre et les esprits. Paris, J. Clattès.

BASTIDE, Roger. (1971) Nascimento de uma religião. In: . As religiões africanas no Brasil, vol. 2. São Paulo, Livraria Ed. Pioneira-EDUSP. . (1973) A macumba paulista. In: Estudos afro-brasileiros. Col. Estudos 18. São Paulo, Ed. Perspectiva.

Brown, Diana. (1985) Uma história da umbanda no Rio. In: ISER (org.). Umbanda e política. Rio de Janeiro, ISER/Ed. Marco Zero.

Camargo, C. P. Ferreira de. (1961) Kardecismo e umbanda. São Paulo, Ed. Pioneira-EDUSP.

Comte, Auguste. (1983) Catecismo positivista. Col. Os Pensadores, $2^{2}$ ed. São Paulo, Ed. Abril.

Concone, Maria Helena V. B. (1987) Umbanda: uma religião brasileira. Col. Religião e Sociedade Brasileira. São Paulo, CER-FFLCH da USP.

GuRvitch, Georges. (1956) La magie, la religion et le droit. In: . $L a$ vocation actuelle de la sociologie. Vol. II. Paris, PUF.

MALINOwsKI, Bronislaw. (1974) Magia, ciencia, religión. Barcelona, Editorial Ariel.

Monteiro, Duglas Teixeira. (1978) Roger Bastide: religião e ideologia. Religião e Sociedade. 13/1. Petrópolis, Ed. Vozes.

Negrão, Lísias Nogueira. (1973) Umbanda e questão moral: formação e atualidade do campo umbandista em São Paulo. São Paulo. Tese de livre-docência. FFLCH-USP.

. (1986) Roger Bastide: do candomblé à umbanda. In: CERU (org.). Revisitando a terra de contrastes: a atualidade da obra de Roger Bastide. São Paulo, CERU-FFLCH da USP.

OrTIZ, Renato. (1991) A morte branca do feiticeiro negro. Umbanda e sociedade brasileira. São Paulo, Ed. Brasiliense.

Velho, Yvonne Alves. (1975) Guerra de Orixá: um estudo de ritual e conflito. Rio de Janeiro, Zahar Ed.

Weber, Max. (1964) Economía y sociedad. Mexico/Buenos Aires, Ed. Fondo de Cultura Económica. 